\title{
BMJ Open Psychiatric disorders following fetal death: a population-based cohort study
}

\author{
Trine Munk-Olsen, ${ }^{1}$ Bodil Hammer Bech, ${ }^{2}$ Mogens Vestergaard, ${ }^{3}$ Jiong Li, ${ }^{2}$ \\ Jørn Olsen, ${ }^{2}$ Thomas Munk Laursen ${ }^{1}$
}

To cite: Munk-Olsen T, Bech BH, Vestergaard M, et al. Psychiatric disorders following fetal death: a population-based cohort study. BMJ Open 2014;4: e005187. doi:10.1136/ bmjopen-2014-005187

- Prepublication history for this paper is available online. To view these files please visit the journal online (http://dx.doi.org/10.1136/ bmjopen-2014-005187).

Received 4 March 2014 Revised 13 May 2014 Accepted 19 May 2014

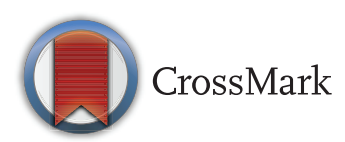

${ }^{1}$ iPSYCH, The Lundbeck Foundation Initiative for Integrative Psychiatric Research, National Center for Register-Based Research, Aarhus University, Aarhus V, Denmark

${ }^{2}$ Section for Epidemiology, Department of Public Health, Aarhus University, Aarhus C, Denmark

${ }^{3}$ Research Unit for General Practice and Section for General Medical Practice, Department of Public Health, Aarhus University, Aarhus, Denmark

Correspondence to Dr Trine Munk-Olsen; tmo@ncrr.dk

\section{ABSTRACT}

Objectives: Women have increased risks of severe mental disorders after childbirth and death of a child, but it remains unclear whether this association also applies to fetal loss and, if so, to which extent. We studied the risk of any inpatient or outpatient psychiatric treatment during the time period from 12 months before to 12 months after fetal death.

Design: Cohort study using Danish population-based registers.

Setting: Denmark.

Participants: A total of 1112831 women born in Denmark from 1960 to 1995 were included. In total, 87 687cases of fetal death (International Classification of Disease-10 codes for spontaneous abortion or stillbirth) were recorded between 1996 and 2010.

Primary and secondary outcome measures: The main outcome measures were incidence rate ratios (risk of first psychiatric inpatient or outpatient treatment).

Results: A total of 1379 women had at least one psychiatric episode during follow-up from the year before fetal death to the year after. Within the first few months after the loss, women had an increased risk of psychiatric contact, IRR: 1.51 ( $95 \%$ Cl 1.15 to 1.99). In comparison, no increased risk of psychiatric contact was found for the period before fetal death. The risk of experiencing a psychiatric episode was highest for women with a loss occurring after 20 weeks of gestation (12 month probability: $1.95 \%, 95 \% \mathrm{Cl} 1.50$ to 2.39 ).

Conclusions: Fetal death was associated with a transient increased risk of experiencing a first-time episode of a psychiatric disorder, primarily adjustment disorders. The risk of psychiatric episodes tended to increase with increasing gestational age at the time of the loss.

\section{INTRODUCTION}

Reproduction and mental health are associated, which has been shown in several studies across different study populations. Childbirth is associated with an increased risk of psychiatric disorders in the mother. ${ }^{1-6}$ Induced abortions have in comparison with studies on childbirths been linked with mental health problems in few, ${ }^{7}$ but not in most studies. $^{8-12}$ The loss of a wanted
Strengths and limitations of this study

- This study calculated the risk of first-time psychiatric episodes after fetal death using Danish population registers, and showed that the risk of psychiatric episodes tended to increase with increasing gestational age at the time of the loss.

- Possible interpretations of these findings could be that fetal loss increases the risk of psychiatric disorders, that fetal loss changes the threshold for hospitalisations or alternatively that factors associated with an underlying mental disorder may cause fetal death.

- Especially early spontaneous abortion rates are difficult to measure and will be underestimated in the present study.

pregnancy is a major life event, which can affect mental health, and spontaneous abortions and stillbirths have been associated with grief, depression, anxiety and social problems. ${ }^{13}$ Loss of a live child is followed by increased risk of severe episodes of psychiatric disorders, ${ }^{15}$ but it remains unclear whether this association also applies to fetal loss and, if so, to which extent.

About $15-20 \%$ of clinically recognised pregnancies abort spontaneously. ${ }^{13}$ A similar fraction is expected to be aborted in the preclinical time period, and $0.5 \%$ of babies reaching 22 weeks of gestation die as stillborns. If fetal loss triggers mental health problems in some women, it could be related to stress, ${ }^{15}$ difficulties in social functioning or changes in family dynamics related to the event. ${ }^{16}$ We aimed to study whether fetal death (spontaneous abortion or stillbirth) is associated with an increased risk of first-time episodes of psychiatric disorders in women. Furthermore, we aimed to study the extent to which such a potential risk may correlate with gestational age.

\section{METHODS}

We conducted a population-based cohort study linking information from different 
nationwide population registers described below. The study population consisted of all women born in Denmark from 1960 to 1995 . Follow-up started on 1 January 1996 and ended on 31 December 2010, at emigration or death or at first psychiatric contact in the study period related to fetal death (including spontaneous abortions and stillbirths), whichever came first. The present cohort study was based on the study population described above and designed through the following steps:

\section{Fetal loss cohort (cohort 1)}

First, we defined a cohort using the information from the national population-based registers including women who were registered as having experienced a fetal death for the first time between 1996 and 2010. All cohort members were followed individually from 12 months before the date of the fetal death until a firsttime psychiatric contact, 12 months after fetal death, date of death, date of emigration or 31 December 2010, whichever came first. First-time psychiatric contacts were recorded as either inpatient admission or outpatient/ emergency treatment for any type of mental disorder. We excluded all women with one or more psychiatric contacts at the start of the follow-up as well as women with records of spontaneous abortions and stillbirths prior to the start of the follow-up period.

\section{Reference cohort (cohort 2)}

Second, we defined a reference cohort to study whether psychiatric morbidity was increased among women experiencing a fetal death compared to a female background population. For each of the exposed women in cohort 1 , we identified three women who fulfilled the following criteria which were also used for cases: they were born in the same year and the same week as the probands; they were alive and residing in Denmark on the day the index person experienced the fetal death (index day).

\section{Data sources}

A personal identification number is assigned to every person living in Denmark, and this number can be used as a unique key for linking information between registries. ${ }^{17}$ The Danish Civil Registration System was introduced in 1968 and holds information on dates of birth, death, migration status and links to legal family members. For the present study, we also used information on parity status (measured as number of live-born children).

Data on fetal death (spontaneous abortions and stillbirths) were obtained from The Danish National Hospital Register. ${ }^{18}$ This register holds information on all treatments at medical hospitals in Denmark (inpatient treatments since 1977, and outpatient treatments since 1995). The following International Classification of Diseases (ICD) codes were used: spontaneous abortion: ICD-10 codes: O021, O021A, O03, ICD-8 codes: $634.61,645.1 \mathrm{x}, 643.0 \mathrm{x}, 643.8 \mathrm{x}$ and $643.9 \mathrm{x}$; stillbirths: ICD-10 codes: Z37.1 (single stillbirth), Z37.4 (twins stillborn), Z37.7 (multiple births, all stillborn), P95, ICD-8 codes: 779.xx. Information on induced firsttrimester and second-trimester abortions (ICD-8 codes: 640, 641, 642. ICD-10 codes: O04, O05, O06) was also collected and included in the present study.

Data concerning the outcome variables, psychiatric inpatient or outpatient treatment were derived from The Danish Psychiatric Central Register. ${ }^{19}$ This register holds information on all treatments at psychiatric hospitals in Denmark (inpatient treatments since 1969 and outpatient treatments since 1995). The diagnostic systems used in this register are the Danish versions of ICD-8 and ICD-10. ${ }^{20}{ }^{21}$ For analyses on psychiatric treatments/contacts, we included all types of psychiatric diagnoses and for subanalyses we divided cases into three groups: adjustment disorders (ICD-10 codes: F43), unipolar depression (ICD-10 codes: F32, 33, 34, 38, 39) and remaining diagnoses (remaining ICD-10 codes). Furthermore, the register was used to derive information on treated psychiatric disorders in parents of the cohort women.

\section{Definition of fetal death}

During the period of 1977-2003, stillbirths in Denmark were defined as the death of a fetus past 28 completed gestational weeks. This definition was changed to 22 completed weeks from 2004. An intrauterine fetal death before these gestational ages was defined as a spontaneous abortion. ${ }^{14}$ Note that the term 'fetal death' is used in the remaining part of the present paper as an 'exposure measure' including spontaneous abortions and stillbirths. In the present study information on gestational age was available for $97.75 \%$ of all cases.

\section{Design and statistical analysis}

Analysis performed in cohort 1 included the calculation of incidence rates (IR) of psychiatric hospital contacts per 1000 person-year under risk. Furthermore, we conducted a survival analysis (Poisson regression) and calculated incidence rate ratios (IRRs); we calculated the IRRs of psychiatric hospital contacts (in 2-month segments) of the 2-year period surrounding the day of the abortive event, while the incidence rate 11-12 months after the abortive event was defined as the reference category. We adjusted the IRRs for age, calendar period, parity status, induced abortion status and family history of formerly treated psychiatric disorders.

By using the supplementary cohort 2, including women from the background population, we made Kaplan-Meier plots to illustrate the probability of having a psychiatric contact within the first 12 months after fetal death compared with incidence rates for the comparable female population.

\section{RESULTS}

Out of the 1112831 women included in the study, 87687 were registered with a first-time recorded 
spontaneous abortion or stillbirth during the study period (1996-2011). Among these, 603 women had at least one psychiatric episode during the year before experiencing the fetal death and 776 had one during the first year after the loss. The women experienced a transient increase in risk of a psychiatric episodes during the first month after the fetal death, IRR 1.51 (95\% CI 1.15 to 1.99$)$, compared with the reference category (11-12 months after the loss, table 1$)$. The majority of women with psychiatric episodes following fetal death were diagnosed with adjustment disorders (table 2).

Additional stratified analyses were performed to describe in further detail the risk of psychiatric episodes within the first month after the fetal death. Results showed that risks were especially high among childless women compared with women with one or more children at the time of the event. Furthermore, we found that women aged 27-34 had the highest risk of experiencing a psychiatric episode after a fetal death (table 3).

Women who experience a fetal loss faced a higher probability of a psychiatric episode during the following 12 months compared with women of the same age who have not experienced such loss (the reference cohort; figure 1). Probabilities of psychiatric episodes varied by gestational age at the time of fetal death: $1.24 \%(95 \%$ CI 0.94 to 1.55 ) for women who experienced a fetal loss before 6 weeks of gestation, $0.78 \%$ (95\% CI 0.71 to 0.84 ) between 6 and 12 weeks of gestation, $0.75 \%(95 \%$ CI 0.55 to 0.97 ) between 13 and 19 weeks of gestation and $1.95 \%$ (95\% CI 1.50 to 2.39) after 20 weeks of gestation.

\section{DISCUSSION}

This large population-based cohort study showed that women experiencing a fetal death had a transient increased risk of primarily adjustment disorders leading to psychiatric hospital contacts lasting for approximately 1 month, especially if the fetal death occured after 20 weeks of gestation. Possible interpretations of these findings could be that fetal loss increases the risk of psychiatric disorders that fetal loss changes the threshold for hospitalisations, or alternatively that factors associated with an underlying mental disorder may cause fetal death.

Our previous findings show that the risk of psychiatric conditions tend to be low during pregnancy, which may indicate that women often plan a pregnancy when they are in good mental health. ${ }^{2}$ In contrast, the risks of psychiatric episodes seem to be increased after childbirth, especially in primiparous women. ${ }^{1422}{ }^{23}$ In the present study, we also found that women without children at the time of the fetal death had higher risks of experiencing mental health problems during the first month after the fetal loss compared with women with one or more children (table 3).

The most common diagnoses after fetal death were adjustment disorders and acute stress reactions (F43 chapter in ICD-10, table 2). This contrasts diagnosisspecific findings after deliveries in general, and in parents who experience loss of a live child, where unipolar depression/affective disorders are the single most common diagnoses. ${ }^{15}$

A previous Norwegian study also found that women who had experienced a spontaneous abortion before 21 gestational weeks had more mental distress up to 6 months after the pregnancy compared with women with induced abortion. In contrast, after 2 and 5 years of follow-up, women who had an induced abortion had higher scores of feelings of guilt, shame but also relief than the miscarriage group. ${ }^{24}$

In the present study we found an increased risk of a psychiatric disorder within the first month after fetal

Table 1 Incidence rate ratios of psychiatric inpatient and outpatient treatment with any psychiatric diagnoses in women having a pregnancy with subsequent fetal death

\begin{tabular}{|c|c|c|c|c|}
\hline $\begin{array}{l}\text { Timing of first psychiatric } \\
\text { contact around time of fetal death }\end{array}$ & $\begin{array}{l}\text { Number } \\
\text { of cases }\end{array}$ & Person-years & $\begin{array}{l}\text { Rate/1000 } \\
\text { person-years }\end{array}$ & $\begin{array}{l}\text { Incidence rate } \\
\text { ratios }\end{array}$ \\
\hline $11-12$ months before & 99 & 13566 & 7.298 & $0.83(0.63$ to 1.09$)$ \\
\hline 9-10 months before & 109 & 13722 & 7.943 & $0.92(0.70$ to 1.20$)$ \\
\hline 7-8 months before & 114 & 13873 & 8.218 & $0.96(0.74$ to 1.25$)$ \\
\hline $5-6$ months before & 94 & 14024 & 6.703 & $0.79(0.60$ to 1.04$)$ \\
\hline 3-4 months before & 93 & 14176 & 6.561 & $0.79(0.60$ to 1.04$)$ \\
\hline $1-2$ months before & 94 & 14323 & 6.563 & $0.80(0.61$ to 1.05$)$ \\
\hline \multicolumn{5}{|l|}{ Fetal death } \\
\hline 1st month after & 91 & 7203 & 12.634 & $1.51(1.15$ to 1.99$)$ \\
\hline 2nd month after & 71 & 7203 & 9.857 & $1.19(0.88$ to 1.60$)$ \\
\hline 3-4 months after & 145 & 14412 & 10.061 & $1.23(0.96$ to 1.57$)$ \\
\hline 5-6 months after & 121 & 14420 & 8.391 & $1.04(0.80$ to 1.34$)$ \\
\hline 7-8 months after & 129 & 14420 & 8.946 & $1.12(0.87$ to 1.44$)$ \\
\hline 9-10 months after & 107 & 14423 & 7.419 & $0.94(0.72$ to 1.23$)$ \\
\hline $11-12$ months after & 112 & 14433 & 7.760 & 1 (ref. category) \\
\hline
\end{tabular}


Table 2 Incidence rate ratios of adjustment disorders, unipolar depression and remaining diagnoses at inpatient and outpatient treatment in women having a pregnancy with subsequent fetal death

\begin{tabular}{|c|c|c|c|c|c|c|}
\hline \multirow{2}{*}{$\begin{array}{l}\text { Timing of psychiatric contact } \\
\text { around time of fetal death }\end{array}$} & \multicolumn{2}{|c|}{$\begin{array}{l}\text { Adjustment disorders } \\
\text { (ICD-10 codes: F43) }\end{array}$} & \multicolumn{2}{|c|}{$\begin{array}{l}\text { Unipolar depression } \\
\text { (ICD-10 codes: } \\
\text { F32,33,34,38,39) }\end{array}$} & \multicolumn{2}{|c|}{ Remaining diagnoses } \\
\hline & $\mathbf{N}^{*}$ & IRR (95\% CI) & $\mathbf{N}^{*}$ & IRR (95\% Cl) & $\mathbf{N}^{*}$ & IRR (95\% Cl) \\
\hline $11-12$ months before & 36 & $0.76(0.49$ to 1.17$)$ & 23 & $1.10(0.60$ to 2.01$)$ & 41 & $0.81(0.53$ to 1.23$)$ \\
\hline 9-10 months before & 38 & $0.80(0.52$ to 1.23$)$ & 21 & $1.00(0.54$ to 1.86$)$ & 50 & $0.99(0.66$ to to 1.47$)$ \\
\hline 7-8 months before & 46 & $0.97(0.64$ to 1.46$)$ & 21 & $1.00(0.54$ to 1.85$)$ & 48 & $0.95(0.64$ to 1.43$)$ \\
\hline 5-6 months before & 28 & 0.59 (0.37 to 0.95$)$ & 14 & 0.67 (0.34 to 1.32$)$ & 52 & $1.04(0.70$ to to 1.54$)$ \\
\hline 3-4 months before & 35 & $0.74(0.47$ to 1.15$)$ & 19 & 0.91 (0.48 to 1.70$)$ & 40 & 0.80 (0.52 to 1.22$)$ \\
\hline $\begin{array}{l}2-1 \text { months before } \\
\text { Fetal death }\end{array}$ & 25 & $0.53(0.32$ to 0.86$)$ & 24 & $1.15(0.63$ to 2.08$)$ & 46 & $0.92(0.61$ to 1.39$)$ \\
\hline 1st month after & 61 & 2.53 (1.72 to 3.72$)$ & 11 & $1.04(0.50$ to 2.17$)$ & 21 & $0.82(0.49$ to 1.37$)$ \\
\hline 2nd month after & 29 & 1.21 (0.76 to 1.93$)$ & 11 & 1.05 (0.50 to 2.18$)$ & 31 & $1.22(0.78$ to 1.92$)$ \\
\hline 3-4 months after & 50 & $1.05(0.70$ to 1.58$)$ & 34 & 1.64 (0.94 to 2.84$)$ & 61 & $1.21(0.83$ to 1.78$)$ \\
\hline 5-6 months after & 54 & $1.15(0.78$ to 1.71$)$ & 31 & $1.51(0.86$ to 2.65$)$ & 37 & $0.75(0.49$ to 1.15$)$ \\
\hline 7-8 months after & 42 & $0.91(0.60$ to 1.38$)$ & 28 & 1.38 (0.78 to 2.46$)$ & 62 & $1.27(0.87$ to 1.86$)$ \\
\hline 9-10 months after & 51 & $1.12(0.75$ to 1.67$)$ & 20 & 1.00 (0.54 to 1.86$)$ & 38 & $0.79(0.52$ to 1.21$)$ \\
\hline $11-12$ months after & 45 & 1 (ref. category) & 20 & 1 (ref. category) & 47 & 1 (ref. category) \\
\hline
\end{tabular}

*Total number of cases: Adjustment disorders: 540 women; Unipolar depression: 277 women; Remaining diagnoses: 574 women.

Note that 12 women received an adjustment and unipolar diagnoses at the index psychiatric contact.

Adjusted for age, calendar period, parity status, previous history of induced abortion and family history of psychiatric disorders.

death. This finding is comparable to the risk of psychiatric episodes in mothers who lost a young child (018 years of age), where the risk was highest shortly after the loss. ${ }^{15}$ A finding which is possibly related to an acute psychological response to a stressful life event. ${ }^{25}$ Also in the present study the risk of psychiatric episodes tended to increase with increasing gestational age, which may indicate a stronger attachment. In contrast, we also found that the risk of psychiatric disorders was high for women with very early losses (figure 1 ). The registration of these early losses is known to be incomplete, except for persons who have received fertility treatment and fetal loss may be a particularly stressful life event for women with an unfulfilled pregnancy wish. ${ }^{26}$

Previous studies have also found an increasing risk of psychiatric symptoms or disorders with increasing gestational age at spontaneous abortion, ${ }^{27} 28$ but not all. ${ }^{29} 30$ Most have measured mental health using questionnaire data, including different scales to measure psychiatric symptoms, and most have found an increased risk of deterioration of mental health in the months immediately after the miscarriage. ${ }^{27} 3132$ Few studies have

Table 3 Stratified incidence rate ratios of psychiatric inpatient and outpatient treatment among women experiencing a fetal death

Overall risk of psychiatric episodes $0-1$ month after fetal death

Stratified analysis

Parenthood

Women with one or more children at time of the fetal loss

Women with no children at time of the fetal loss

Stratified analysis

Age

Age group $\leq 26$ years

Age group 27-34 years

$1.51(1.15$ to 1.99$)$

Age group $35+$ years

Reference category: 11-12 months after exposure.

Cohort 1: Adjusted for age, calendar period, parity status, previous history of induced abortion and family history of psychiatric disorders.

Parity status, induced abortion history and family history of psychiatric disorders: time-dependent variables.

Cohort 2: Probability of psychiatric contacts 12 months after a pregnancy resulting in fetal death:

$<6$ weeks: $1.24 \%$ (95\% Cl 0.94 to 1.55$), \mathrm{N}=64$ cases;

$6-12$ weeks: $0.78 \%(95 \% \mathrm{Cl} 0.71$ to 0.84$), \mathrm{N}=532$ cases;

13-19 weeks: $0.75 \%(95 \% \mathrm{Cl} 0.55$ to 0.97$), \mathrm{N}=51$ cases;

20 weeks+: $1.95 \%$ (95\% Cl 1.50 to 2.39$), \mathrm{N}=72$ cases.

Controls/reference population: $0.63 \%(95 \% \mathrm{Cl} 0.60$ to 0.66$)$. Thirty-one of the 776 cases had missing information on gestational age, and 26 had late entry and were excluded from the analyses. 


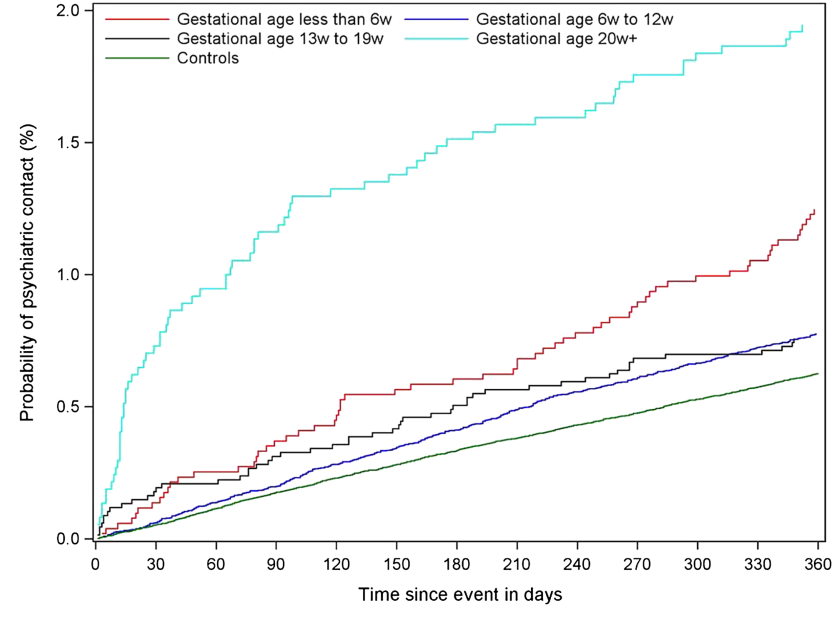

Figure 1 Unadjusted absolute risk measured as percentages of first-time psychiatric inpatient or outpatient treatment following spontaneous abortion and stillbirth.

followed women up to 12 months after the miscarriage. Janssen $e t a l^{27}$ compared women after miscarriage with women who gave birth to live-born babies. After 6 months, these two groups differed substantially according to depression scores, anxiety scores and somatisation, but the differences were not statistically significant after 12 months, which is in line with the results reported by Beutel et al. ${ }^{33}$ A recent study from China compared women who miscarried (miscarriage $<24$ weeks of gestation) with a group of non-pregnant women, using the 12-item General Health Questionnaire (GHQ-12) and the Beck Depression Inventory (BDI). The miscarrying women had a significantly higher proportion of GHQ-12 scores of $\geq 4$ initially and after 6 and 12 months compared to non-pregnant controls, while the proportion of BDI scores $\geq 12$ were higher at the start of follow-up, but not at the end of follow-up 12 months after miscarriage. ${ }^{34}$ Klier $e t a l^{0}$ and Neugebauer $e t a l^{29}$ found that miscarrying women had a 2.5-fold and fivefold higher risk for an episode of major and minor depressive disorder, respectively, 6 months after miscarriage compared to control women. Note that, in comparison to the aforementioned results, our study had severe endpoints, measured as psychiatric treatment at inpatient or outpatient facilities.

We used data from The National Hospital Register where the positive predictive value of the diagnosis of spontaneous abortions in a clinically recognised pregnancy is around $95-97 \%,{ }^{35}$ Note that early spontaneous abortion rates are notoriously difficult to measure and will be underestimated. ${ }^{36}$ After 8 weeks of gestational age, most spontaneous abortions are known to the women and documented. ${ }^{37}{ }^{38}$ In a Danish study using registry data on spontaneous abortions, Nybo Andersen et $a l^{39}$ estimated that about $13 \%$ of clinical recognised pregnancies intended to be carried to term ended in fetal loss. However, Buss et $a t^{40}$ found that about $30 \%$ of the spontaneous abortions reported by women are not recorded in The Danish National Patient Register. If under-reporting of fetal loss is related to a lower threshold for hospitalisation in women with psychiatric disorders, this could explain our results.

Our outcome measure was defined as any type of psychiatric disorder treated at an inpatient or outpatient psychiatric treatment facility. For this reason, the rates of psychiatric disorders may be underestimated, and our results do not provide information on minor self-treated mental problems or mental health problems treated in primary care.

Residual confounding cannot be ruled out since unmeasured patient characteristics may have influenced our results. The present study did for example, not include information on lifestyle factors such as smoking or alcohol use, which has been shown to increase the risk of spontaneous abortions. ${ }^{41}$ Moderate alcohol intake during pregnancy and risk of fetal death ${ }^{42}$ may also be associated with the outcome in our study. Similarly, we did not have information on use of antidepressants and antipsychotics, which may also confound the observed results. Several other factors have been identified as potential causes of spontaneous abortions, ${ }^{43}$ and some of these may also be risk factors for mental disorders. However, using a design with internal comparisons among women who experienced fetal death during a relatively short observation period reduces confounding to a minimum, that is, factors such as medicine use and substance abuse. There is a potential bias in calculating IRRs before the exposure (fetal death), since the analyses is conditional on the survival of the women in the 12 months prior to the event. However, such bias is unlikely given the relatively young age of the cohort.

\section{CONCLUSION}

Fetal death was associated with a transient increased risk of experiencing a first-time episode of a psychiatric disorder measured as inpatient or outpatient contacts for any type of mental disorder at a psychiatric treatment facility. The most common diagnoses after fetal death were adjustment disorders. The risk of psychiatric episodes tended to increase with increasing gestational age at the time of the loss, with spontaneous abortions before 6 weeks of gestation being the exception. The excess risk period is short, but of rather high magnitude, and healthcare personnel should be aware of the increased risk of mental health problems following a fetal death, regardless of its cause.

Contributors TM- 0 and TML were involved in the initial phase of planning the study. TM-0 wrote the first and subsequent drafts of the manuscript. TML conducted the statistical analyses. All authors contributed to methodological considerations and the specific design of the study as well as making critical revisons to the all versions of the manuscript.

Funding This study was supported by unrestricted research grants from The Lundbeck Foundation: iPSYCH (The Lundbeck Foundation Initiative for Integrative Psychiatric Research) and MEPRICA (Mental Health in Primary Care). $\mathrm{JL}$ was supported by a grant from European Research Council (ERC-StG-2010260242-PROGEURO). 
Competing interests None.

Ethics approval All personal identifiers were removed and replaced with a sequential number in the final data set, and the protocol was approved by The Danish Data Protection Agency.

Provenance and peer review Not commissioned; externally peer reviewed.

Data sharing statement No additional data are available.

Open Access This is an Open Access article distributed in accordance with the Creative Commons Attribution Non Commercial (CC BY-NC 4.0) license, which permits others to distribute, remix, adapt, build upon this work noncommercially, and license their derivative works on different terms, provided the original work is properly cited and the use is non-commercial. See: http:// creativecommons.org/licenses/by-nc/4.0/

\section{REFERENCES}

1. Bergink V, Lambregtse-van den Berg MP, Koorengevel KM, et al. First-onset psychosis occurring in the postpartum period: a prospective cohort study. J Clin Psychiatry 2011;72:1531-7.

2. Munk-Olsen T, Laursen TM, Pedersen CB, et al. New parents and mental disorders: a population-based register study. JAMA 2006;296:2582-9.

3. Munk-Olsen T, Laursen TM, Mendelson T, et al. Risks and predictors of readmission for a mental disorder during the postpartum period. Arch Gen Psychiatry 2009;66:189-95.

4. Kendell RE, Chalmers JC, Platz C. Epidemiology of puerperal psychoses. Br J Psychiatry 1987;150:662-73.

5. Harlow BL, Vitonis AF, Sparen P, et al. Incidence of hospitalization for postpartum psychotic and bipolar episodes in women with and without prior prepregnancy or prenatal psychiatric hospitalizations. Arch Gen Psychiatry 2007;64:42-8.

6. Wisner KL, Bogen DL, Sit D, et al. Does fetal exposure to SSRIs or maternal depression impact infant growth? Am J Psychiatry 2013:170:485--93.

7. Coleman PK. Abortion and mental health: quantitative synthesis and analysis of research published 1995-2009. Br J Psychiatry 2011;199:180-6.

8. Charles VE, Polis CB, Sridhara SK, et al. Abortion and long-term mental health outcomes: a systematic review of the evidence. Contraception 2008;78:436-50.

9. American Psychological Association, Task Force on Mental Health and Abortion. Report of the Task Force on Mental Health and Abortion. 2008. Washington, DC. http://www.apa.org/pi/wpo/mentalhealth-abortion-report.pdf.

10. Academy of Medical Royal Colleges. National Collaborating Centre for Mental Health. Induced abortion and mental health: a systematic review of the mental health outcomes of induced abortion, including their prevalence and associated factors. 2011.

11. Munk-Olsen T, Laursen TM, Pedersen CB, et al. Induced first-trimester abortion and risk of mental disorder. N Engl J Med 2011;364:332-9.

12. Munk-Olsen T, Laursen TM, Pedersen CB, et al. First-time first-trimester induced abortion and risk of readmission to a psychiatric hospital in women with a history of treated mental disorder. Arch Gen Psychiatry 2012;69:159-65.

13. Lok IH, Neugebauer R. Psychological morbidity following miscarriage. Best Pract Res Clin Obstet Gynaecol 2007;21:229-47.

14. Flenady V, Middleton P, Smith GC, et al. Stillbirths: the way forward in high-income countries. Lancet 2011;377:1703-17.

15. Li J, Laursen TM, Precht DH, et al. Hospitalization for mental illness among parents after the death of a child. $N$ Engl J Med 2005;352:1190-6.

16. Rogers $\mathrm{CH}$, Floyd FJ, Seltzer MM, et al. Long-term effects of the death of a child on parents' adjustment in midlife. J Fam Psychol 2008;22:203-11.

17. Pedersen $\mathrm{CB}$, Gotzsche $\mathrm{H}$, Moller JO, et al. The Danish Civil Registration System. A cohort of eight million persons. Dan Med Bull 2006;53:441-9.

18. Andersen TF, Madsen M, Jorgensen J, et al. The Danish National Hospital Register. A valuable source of data for modern health sciences. Dan Med Bull 1999;46:263-8.

19. Mors O, Perto GP, Mortensen PB. The Danish Psychiatric Central Research Register. Scand J Public Health 2011;39(7 Suppl):54-7.
20. World Health Organization. Klassifikation af sygdomme; Udvidet dansk-latinsk udgave af verdenssundhedsorganisationens internationale klassifikation af sygdomme. 8 revision, 1965 Classification of diseases: extended Danish-Latin version of the World Health Organization International Classification of Diseases. 8th revision. 1965]. 1st edn. Copenhagen: Danish National Board of Health, 1971.

21. World Health Organization. WHO ICD-10: Psykiske lidelser og adfærdsmæssige forstyrrelser. Klassifikation og diagnosekriterier [WHO ICD-10: mental and behavioural disorders. Classification and Diagnostic Criteria]. Copenhagen: Munksgaard Danmark, 1994.

22. Blackmore ER, Jones I, Doshi M, et al. Obstetric variables associated with bipolar affective puerperal psychosis. $\mathrm{Br} J$ Psychiatry 2006;188:32-6.

23. Videbech $P$, Gouliaev $G$. First admission with puerperal psychosis: 7-14 years of follow-up. Acta Psychiatr Scand 1995:91:167-73.

24. Broen AN, Moum T, Bodtker AS, et al. The course of mental health after miscarriage and induced abortion: a longitudinal, five-year follow-up study. BMC Med 2005;3:18.

25. McEwen BS. Protective and damaging effects of stress mediators. N Engl J Med 1998;338:171-9.

26. Baldur-Felskov B, Kjaer SK, Albieri V, et al. Psychiatric disorders in women with fertility problems: results from a large Danish Register-Based Cohort Study. Hum Reprod 2012;28: 683-90.

27. Janssen $\mathrm{HJ}$, Cuisinier MC, Hoogduin KA, et al. Controlled prospective study on the mental health of women following pregnancy loss. Am J Psychiatry 1996;153:226-30.

28. Cuisinier MC, Kuijpers JC, Hoogduin CA, et al. Miscarriage and stillbirth: time since the loss, grief intensity and satisfaction with care. Eur J Obstet Gynecol Reprod Biol 1993;52:163-8.

29. Neugebauer $R$, Kline J, Shrout $P$, et al. Major depressive disorder in the 6 months after miscarriage. JAMA 1997;277:383-8.

30. Klier CM, Geller PA, Neugebauer R. Minor depressive disorder in the context of miscarriage. J Affect Disord 2000;59:13-21.

31. Neugebauer R. Depressive symptoms at two months after miscarriage: interpreting study findings from an epidemiological versus clinical perspective. Depress Anxiety 2003;17:152-61.

32. Boyle FM, Vance JC, Najman JM, et al. The mental health impact of stillbirth, neonatal death or SIDS: prevalence and patterns of distress among mothers. Soc Sci Med 1996;43:1273-82.

33. Beutel M, Deckardt R, von RM, et al. Grief and depression after miscarriage: their separation, antecedents, and course. Psychosom Med 1995;57:517-26.

34. Lok IH, Yip AS, Lee DT, et al. A 1-year longitudinal study of psychological morbidity after miscarriage. Fertil Steril 2010;93:1966-75

35. Lohse SR, Farkas DK, Lohse N, et al. Validation of spontaneous abortion diagnoses in the Danish National Registry of Patients. Clin Epidemiol 2010;2:247-50.

36. Wang JX, Norman RJ, Wilcox AJ. Incidence of spontaneous abortion among pregnancies produced by assisted reproductive technology. Hum Reprod 2004;19:272-7.

37. Wilcox AJ, Treloar AE, Sandler DP. Spontaneous abortion over time: comparing occurrence in two cohorts of women a generation apart. Am J Epidemiol 1981;114:548-53.

38. Heidam LZ, Olsen J. Self-reported data on spontaneous abortions compared with data obtained by computer linkage with the hospita registry. Scand J Soc Med 1985;13:159-63.

39. Nybo Andersen AM, Wohlfahrt J, Christens P, et al. Maternal age and fetal loss: population based register linkage study. BMJ 2000;320:1708-12.

40. Buss L, Tolstrup J, Munk C, et al. Spontaneous abortion: a prospective cohort study of younger women from the general population in Denmark. Validation, occurrence and risk determinants. Acta Obstet Gynecol Scand 2006;85:467-75.

41. Nielsen A, Hannibal CG, Lindekilde BE, et al. Maternal smoking predicts the risk of spontaneous abortion. Acta Obstet Gynecol Scand 2006;85:1057-65.

42. Andersen AM, Andersen PK, Olsen J, et al. Moderate alcohol intake during pregnancy and risk of fetal death. Int $J$ Epidemiol 2012;41:405-13.

43. Kumar S. Occupational, environmental and lifestyle factors associated with spontaneous abortion. Reprod Sci 2011;18: 915-30. 